Derecho \& Realidad

Vol. 13 - Núm. 25 •Enero-Junio de 2015

Págs. 145-164 • ISSN:1692-3936

\title{
Ambientes favorables para el ejercicio de la democracia en la escuela*
}

\author{
Enabling environments for the exercise \\ of democracy in school
}

\author{
José Eriberto Cifuentes Medina** \\ eribertocifuentes@hotmail.com
}

\section{Resumen}

El artículo analiza la relación entre la democracia y sus ambientes favorables de vivencia en la escuela. Además presenta la manera como los agentes educativos establecidos por la ley se gobiernan -influenciados en gran parte por los intereses de los profesores, agentes de la educación para la democraciay su incidencia para la sociedad, que se experimenta desde la misma escuela. Se exploran aspectos de los ambientes que se manifiestan acerca de la democracia y su ejercicio, a fin de fortalecer las competencias cívicas y ciudadanas de los futuros ciudadanos y promover la construcción de sus deberes y derechos como estudiantes para participar de las decisiones de la

* Artículo de reflexión, presentado con algunas modificaciones como ponencia en el XI Congreso Latinoamericano de Humanidades "Interculturalidad e inclusión en la época de la globalización", celebrado los días 3, 4 y 5 de abril de 2014 en la Universidad Santo Tomás, Bogotá, Colombia.

** Magíster en Educación, Especialista en Educación con énfasis en Evaluación Educativa, Licenciado en Teología, Licenciado en Filosofía y Educación Religiosa, Universidad Santo Tomás. Docente investigador de la Escuela de Ciencias Humanísticas y de Educación de la UPTC. 
escuela, de forma tal que se favorezcan el desarrollo y la promoción de los derechos humanos.

\title{
Palabras clave
}

Democracia, escuela, educación, maestro, estudiantes.

\begin{abstract}
This paper examines the relationship between democracy and its enabling environments in school. It also presents how educational agents established by law are governed-largely influenced by the interests of teachers, which are the educational agents for democracy-and their impact on society that is experienced from the school. It explores aspects of environments on democracy and its exercise in order to strength civic and citizenship skills of future citizens and to promote the construction of their duties and rights as students, to participate in school decisions, favoring development, promotion and defense of human rights.
\end{abstract}

\section{Keywords}

Democracy, school, education, teacher, student. 


\section{Introducción}

El artículo presenta una reflexión sobre la necesidad de renovar el ejercicio de la democracia en la escuela y también sobre la manera como esta aporta a la formación integral de los estudiantes de las diferentes instituciones educativas que conforman toda su vida escolar desde la infancia hasta la universidad. También se analiza si en realidad se vive un proceso de democracia que aporte a la formación ciudadana de los educandos, o si, por el contrario, solo se lleva a cabo por dar cumplimiento a la legislación, al manual de convivencia y a una tradición que se ha forjado en escuelas, colegios y universidades, pero que ha llevado a deformar la verdadera democracia, a la cual tiene derecho un ciudadano a partir de su mayoría de edad.

Se abordan algunas de las concepciones de democracia, desde la perspectiva de algunos autores, también la historia del voto en Colombia, algunas leyes nacionales e internacionales sobre la democracia, el desarrollo de la democracia en la escuela, la forma de enseñanza de la democracia en las escuelas, el maestro especialista del proceso, el gobierno escolar, e igualmente se plantea lo que debería corregirse en el proceso electoral en el ejercicio de la democracia.

El gobierno escolar es la forma de vivenciar los procesos de democracia en la escuela por parte de los agentes educativos, enseñados por los padres de familia en cada hogar, implementados por el docente en el aula, vividos con los compañeros y aprobados en el manual de convivencia escolar. Una vez terminados sus estudios, los estudiantes se enfrentan a la realidad democrática de la sociedad y de acuerdo con sus bases educativas recibidas, podrán elegir o ser elegidos de manera democrática, es decir, que lo enseñado en la casa y vivido en la escuela, se proyecta a la sociedad, que se espera sea para el beneficio común de las personas y progreso de los pueblos.

\section{Concepciones sobre la democracia}

El término democracia viene del griego: Demos: pueblo y Kratos: poder o gobierno; es decir: "poder del pueblo" (Casas, 2003, p. 15). "En sentido amplio la democracia es una forma de convivencia social en la que todos sus habitantes son libres e iguales ante la ley y las relaciones sociales se establecen de acuerdo a mecanismos contractuales desde el punto de vista filosófico en la vida cotidiana" (Rodríguez, 2008, p. 20). Para la escuela se aplican las dos, al elegir sus representantes, cada agente educativo se siente allí incorporado para defender o apoyar sus intereses, pero asegurando la igualdad, la libertad, los valores humanos y las condiciones de una vida digna.

En cuanto a concepción del mundo, nos conduce a uno de los ideales sublimes que el hombre intenta consolidar en la historia; ideal de la no arbitrariedad o autoritarismo, 
es decir, que exista participación del pueblo en sus decisiones y que las personas sean consideradas ciudadanos con derechos y deberes, con derecho a elegir y ser elegidos para gobernar, desde los diferentes organismos que componen el gobierno escolar y los demás de la escuela.

La democracia es un sistema de gobierno y un estilo de vida. Un sistema de gobierno se caracteriza porque es el pueblo el que toma las decisiones más importantes mediante la elección periódica de sus autoridades, a través de un voto libre, igualitario y secreto. Abraham Lincoln afirmaba: "La democracia es el gobierno del pueblo, por el pueblo y para el pueblo" (Rodríguez, 2008, p. 4), de esta manera ha de existir un reconocimiento y respeto a los derechos fundamentales de las personas; por eso la democracia ha de ser un estilo de vida del estudiante desde el aula de clase. Eso significa que los comportamientos y actitudes personales hacen posible que un ciudadano pueda contribuir a perfeccionar la democracia, pero que se puede iniciar desde los procesos de la escuela y también de la familia.

Aristóteles afirma: "La libertad es el principio fundamental de la constitución democrática. Esto es lo que acostumbra a decirse, implicando ello que solo en este régimen político pueden los hombres participar de la libertad, y a este fin apunta, según se afirma toda democracia" (Aristóteles, 2000, p. 30). Ahora bien, uno de los caracteres de la libertad es el alternarse con la obediencia y el mando, y en efecto, "la justicia democrática, consiste en la igualdad por el número y por el mérito, y siendo esto lo justo, de necesidad tiene que ser soberana la masa popular y estimarse como final y justa la decisión de la mayoría" (Aristóteles, 2000, p. 30). De acuerdo con esta teoría, todos los ciudadanos han de estar en pie de igualdad, aunque lo que resulta en las democracias es que los pobres tienen más poder que los ricos, puesto que son más en número y la decisión de la mayoría es soberana.

Jhon Locke en su obra Tratado sobre el gobierno civil, demuestra que todo gobierno ha de estar fundamentado en un contrato entre el soberano y los súbditos. Un buen gobierno debe tener separación de poderes: el ejecutivo, legislativo y judicial. Locke dice: "la razón enseña a los hombres las leyes de la naturaleza como verdades eternas que dan lugar a los derechos naturales e inalienables del individuo" (Locke, 1995, p. 30). Igualmente, Rousseau, en su obra El contrato social, expresa que: "los ciudadanos de una nación tienen igualdad de derechos y participación de la soberanía popular, cuya expresión es la ley la cual es el resultado de la voluntad general" (Rousseau, 2000, p. 30).

Montesquieu en El espíritu de las leyes, señala que: "la influencia del clima y del ambiente en la organización política de los pueblos, defendió el gobierno constitucional y la decisión del poder público" (Montesquieu, 2000, p. 30). Estas afirmaciones deben contribuir a una correcta organización del gobierno escolar con la participación 
de los estudiantes en las decisiones de la escuela, como ejemplo de proyección al futuro de la organización de su comunidad, ciudad, departamento y nación. Una adecuada educación democrática desde la escuela puede garantizar jóvenes y personas que, elegidas por el pueblo para que lo represente, puedan gobernar en pro del bien común.

Así mismo, Platón (2000), Aristóteles y los estoicos hablan de la ley natural, que cobra importancia en la escolástica con Santo Tomás de Aquino, Francisco de Victoria y otros, quienes elaboran las bases filosóficas de la ley natural que evoluciona en la Edad Moderna con Thomas Hobbes que la transforma en una doctrina estructurada, conocida hoy como derecho natural; y después, con Locke y Rousseau, consolida los elementos de la democracia desde la perspectiva filosófica.

\subsection{Educar para la democracia}

La democracia y la formación ciudadana son conceptos muy estrechamente unidos. González et al. (1998), citando a Kaplan (1997) y Dewey (1985), basándose en consideraciones sobre la democracia como forma de vida, denominan educación democrática: "aquella capaz de proporcionar, no meramente información sobre el mundo, sino una perspectiva clara de la forma que ciertas elecciones han afectado a nuestro modo de vida" (González et al., 1998, p. 59), de tal manera que aporte a los alumnos un conocimiento y "un sentimiento de conexión entre lo que la sociedad escoge hacer y el control que es capaz de ejercer sobre las consecuencias de sus decisiones" (González et al., 1998, p. 59). Por ello, los estudiantes han de educar su conciencia para obrar con rectitud al elegir y ser elegido, han de tener la responsabilidad para asumir las consecuencias de su proceder al gobernar, han de asumir liderazgo y compromiso para representar dignamente a quienes se lo confiaron; en otras palabras, los estudiantes se han de convertir en líderes.

Por ello, vivir en democracia y para la democracia requiere actitudes de aceptación, valoración y respeto, participación y colaboración entre los estudiantes y los actores educativos. La preparación que permite alcanzar un nivel deseable en esas actitudes se ha de gestar y adquirir en la escuela, allí debe ser posible obtener conocimientos y hábitos de convivencia democrática, así como experiencias de participación responsable en actitudes e instancias sociales y posteriormente del Estado.

Más que compartir valores será preciso compartir actitudes, pues un objetivo clave de esta participación ha de ser el desarrollo de la reflexión. Esta deliberación ha de conducir a los estudiantes a preguntarse, a buscar respuestas y evaluar el propósito y significado de sus propias actividades. Dicha preocupación y los hábitos de participación responsable en actividades colectivas irán contribuyendo a la creación de un clima en el aula extrapolable al exterior, es decir, su familia y la comunidad 
donde vive. Debe llevar a los estudiantes a prepararse para asumir compromisos desde la misma vida en adelante, mantener sus opiniones, asumir retos, confrontar ideas y habituarse a la discrepancia con prudencia, respeto, argumentos, rectitud, de manera que conduzca al bien personal y colectivo.

\subsection{Educación y democracia}

La política nacional de educación, por principio, ha de fundarse en la práctica de la democracia, por ello Dewey afirma: "que la educación y la democracia tienen una relación recíproca" (Dewey, 1990, p. 54), no es solo que es en sí misma un principio educativo, sino que la democracia no puede durar y menos desarrollarse, sin la educación. Las dos estrechan sus manos y contribuyen desde la escuela a la formación de estudiantes y en adelante ciudadanos educados democráticos con un alto compromiso social.

La democracia es "entendida como la forma de organización del Estado, de las entidades territoriales, municipales y la escuela en la cual el ejercicio del poder reside básicamente en la participación organizada del pueblo, ya sea de manera directa o a través de sus representantes legítimos" (Bernal, 1995, p. 22), en consecuencia el predominio del pueblo es el gobierno político del Estado. Todos aceptan que el poder solamente es legítimo en cuanto tiene origen en la autoridad del pueblo, que se ejerce con su consentimiento. Por ello se les reconoce a los estudiantes, que elegidos por sus compañeros, se constituyen en un poder legítimo de representación en pro del desarrollo común y en defensa de los intereses colectivos de quienes fueron sus electores.

La relación de la democracia y la educación se da en la práctica cuando se manifiesta en la organización del gobierno escolar el comportamiento social de la escuela, por medio del gobierno interno y en la estructura, también en los contenidos de los programas de estudio de las asignaturas de manera especial de Ciencias Sociales, Ética, Democracia, entre otras, donde se debe hacer especial hincapié en el desarrollo de las habilidades ciudadanas y democráticas. En contra del ejercicio de la democracia en la escuela está el proselitismo partidista, la falta de diálogo constructivo y la imposición de ideas propias de los profesores, malos ejemplos de gobernantes, ideas de otros países y épocas, contrarias al espíritu y a la esencia de los principios de la educación nacional para la democracia, que, por cierto, se hace necesario que sea un elemento transversal e interdisciplinar.

La práctica de la democracia en la escuela, la educación allí impartida y la vivencia de la democracia al igual que el gobierno, deben conducirnos a los colombianos a tener la posibilidad de derrotar las arbitrariedades y evitar las tiranías, para construir una verdadera sociedad democrática. Por supuesto que este principio es contario a la 
forma elitista tradicional de ingreso a las instituciones escolares; exige, en cambio, una visión política y acciones operativas en el campo de la enseñanza, pero se puede lograr, puesto que el hombre educado es capaz de transcender las barreras de lo contrario a la democracia, en pro de una convivencia entre la comunidad de humanos.

\subsection{Historia del voto en Colombia}

Es importante hablar sobre la forma como los ciudadanos ejercen la democracia y como este proceso se asemeja en las instituciones educativas, para elegir sus representantes estudiantiles, ante los diferentes estamentos en la escuela. De esta manera se presenta una breve historia del voto:

Tabla 1. Historia del voto en Colombia

\begin{tabular}{|c|l|}
\hline Año & \multicolumn{1}{c|}{ Situación histórica del voto } \\
\hline 1810 & $\begin{array}{l}\text { Desde las guerras de independencia los patriotas lucharon por el derecho a elegir, } \\
\text { sin embargo en las nuevas constituciones, quedaron excluidos los: esclavos, } \\
\text { analfabetas, pobres y las mujeres, era excluyente. }\end{array}$ \\
\hline 1853 & $\begin{array}{l}\text { Incluye a hombres mayores de 21 años: la constitución de este año, tras } \\
\text { enfrentamiento durante el siglo XIX entre quienes defendían el derecho al voto, } \\
\text { quienes decían que debía ser exclusivo de los ricos y de los que sabían leer y } \\
\text { escribir, amplió el sufragio a hombres de más de 21 años y a los descendientes de } \\
\text { los esclavos. }\end{array}$ \\
\hline 1886 & $\begin{array}{l}\text { A partir de este año se volvió a quitar el derecho al voto de los analfabetas a menos } \\
\text { que tuvieran propiedades o altos ingresos. }\end{array}$ \\
\hline 1910 & $\begin{array}{l}\text { La reforma constitucional de este año mantuvo el esquema de que solo pudieran } \\
\text { votar para presidente quienes supieran leer y escribir y tuvieran una renta anual de } \\
\text { 300 pesos o propiedad raíz de 1.000 pesos. }\end{array}$ \\
\hline 1931 & $\begin{array}{l}\text { En este año se determinó que en cada mesa de votación hubiera un recipiente con } \\
\text { tinta indeleble o cualquier otra solución química de este tipo, para que el votante } \\
\text { untara el dedo índice. }\end{array}$ \\
\hline 1936 & $\begin{array}{l}\text { Este año se otrogó finalmente el derecho al voto a todos los hombres adultos, es } \\
\text { decir, a todos los mayores de 21 años. }\end{array}$ \\
\hline 1954 & $\begin{array}{l}\text { En este año se le dio el derecho a elegir y ser elegida la mujer. La primeroa cédula } \\
\text { de esta clase fue expedida en 1956 a Carola Correa, esposa del general Gustavo } \\
\text { Rojas Pinilla. Las mujeres votan por primera vez en el plebiscito de 1957. }\end{array}$ \\
\hline 1975 & $\begin{array}{l}\text { Se rebajó en tres años el derecho a recibir la cédula, que hasta entonces se otrogaba } \\
\text { a los 21 años. Fue así como la mayoría de edad se adquirió a los 18 años. }\end{array}$ \\
\hline 1990 & $\begin{array}{l}\text { Para las elecciones presidenciales de este año se imprimió el primer tarjetón, } \\
\text { quedaron atrás las papeletas en las que iban los nombres de los candidatos y se } \\
\text { guardaban en sobres pequeños. Estas papeletas facilitaron muchos fraudes, porque } \\
\text { habían quienes las cambiaban antes de introducir en la urna. }\end{array}$ \\
\hline 2004 & $\begin{array}{l}\text { La Ley Estatutaria 892 de este año estableció el voto electrónico, que por razones } \\
\text { de presupuesto no ha sido aplicado. }\end{array}$ \\
\hline
\end{tabular}


El voto se consagra en el espacio de la escuela a partir de la ley 115 de 1994 o Ley General de Educación, reglamentada en el Decreto 1860 de 1994, sobre pedagogía y organización del servicio educativo. También se contempla en el proyecto educativo institucional, en el manual de convivencia, en los proyectos transversales y demás documentos de la escuela para hacerlo efectivo en el desarrollo de la vida escolar de los estudiantes.

\subsection{Legislación de Colombia que permite la enseñanza y promueve la democracia}

Esta se constituye en un verdadero reto en los tiempos actuales, en especial en quienes son elegidos para gobernar nuestro país, lo que se ve reflejado en los adolescentes y jóvenes. Por eso es necesario abordar la legislación colombiana e institucional para averiguar acerca de la enseñanza de la democracia, con el fin de formar y educar a los estudiantes para que sean auténticos ciudadanos, capaces de ejercer de manera adecuada la democracia.

Tabla 2. Leyes sobre la enseñanza de la democracia y el gobierno escolar

\begin{tabular}{|c|c|}
\hline NORMA & CONTENIDO \\
\hline $\begin{array}{l}\text { Constitución } \\
\text { Política de } \\
\text { Colombia } \\
\text { de } 1991\end{array}$ & $\begin{array}{l}\text { En sus artículos } 13 \text { y } 22 \text { promulga los derechos de igualdad, equidad y paz son tan } \\
\text { necesarios para la convivencia armónica pero en realidad son vulnerados a diario; o que } \\
\text { hace necesario trabajar en su promoción: } \\
\text { En su artículo } 41 \text { promulga la obligatoriedad de la enseñanza y la instrucción cívica: } \\
\text { "En todas las instituciones de educación, oficiales o privadas, serán obligatorios el } \\
\text { estudio de la Constitución y de la instrucción cívica, así mismo se fomentarán las } \\
\text { prácticas democráticas para el aprendiz de los principios y valores de la participación } \\
\text { ciudadana. El estado divulgará la Constitución". También el artículo 08, acerca de la } \\
\text { educación. }\end{array}$ \\
\hline $\begin{array}{c}\text { Ley } \\
\text { General de } \\
\text { Educación } \\
\text { Ley } 115 \\
\text { de } 1994\end{array}$ & $\begin{array}{l}\text { La Ley General de Educación de conformidad con el Art. } 67 \text { de la Constitución Nacional } \\
\text { define y desarrolla la organización y prestación de la educación hace referencia a la } \\
\text { articulación de los procesos y estructuras para alcanzar los objetivos de la educación. Art. } \\
5 \text { Fines de la educación: de conformidad con el Art. } 07 \text { de la Constitución se desarrolla } \\
\text { atendiendo aspectos como: el desarrollo de la personalidad, el respeto, a la paz y a los } \\
\text { demás derechos, lo cual se logrará mediante las prácticas democráticas partiendo del } \\
\text { ámbito escolar e irradiando este aprendizaje hacia otros espacios de acción del estudiante. } \\
\text { En el Art. } 13 \text { de la Ley 115: objetivos comunes de todos los niveles: en su numeral c) } \\
\text { hace referencia al fomento de las prácticas democráticas y de participación y organización } \\
\text { ciudadana. Art. } 21 \text { objetivos de la educación básica: en su numeral a) Sobre la formación } \\
\text { de valores fundamentales para la convivencia en una sociedad democrática, participativa } \\
\text { y pluralista, resalta la importancia de trabajar en la construcción de dichos aspectos, } \\
\text { con los estudiantes, para asegurar su desarrollo social. }\end{array}$ \\
\hline Ley 115 & $\begin{array}{l}\text { En el título VII, De los establecimientos educativos, en el capítulo II, nos habla del } \\
\text { gobierno escolar, su conformación por el rector, cosejo directivo y consejo académico, } \\
\text { al igual que señala las funciones de cada uno. }\end{array}$ \\
\hline $\begin{array}{c}\text { Decreto } \\
1860\end{array}$ & $\begin{array}{l}\text { En el capítulo IV, El gobierno escolar y la organización industrial, que desde el artículo } \\
18 \text { y hasta el 32, aparte de lo señalado por la Ley } 115 \text {, amplía al personero estudiantil. } \\
\text { Al consejo de estudiantes e incluso las asociaciones de padres de familia y estudiantes. }\end{array}$ \\
\hline
\end{tabular}


Para que en Colombia se emprenda un cambio en las instituciones educativas, se requiere la construcción de una ética nueva sobre la base de una mayor participación y pluralismo en los entes de los establecimientos educativos por quienes hacen parte del ejercicio de la democracia. Tanto la Constitución, como la Ley General de Educación y el Decreto 1860 de 1994, brindan un apoyo a la enseñanza de las competencias democráticas en la escuela a los estudiantes, como el ejercicio de estas a través de la organización del gobierno escolar en cada institución. Este ejercicio electoral dentro de la institución, donde se permite elegir y ser elegido, ha de afianzar el liderazgo en los estudiantes, la rectitud al realizar su campaña y una digna representación, a fin de promover los derechos y favorecer los deberes de sus compañeros en los diferentes organismos que señala la ley.

\subsection{Una comunidad escolar participativa para la formación democrática}

Se extiende desde el aula y demás instancias, desde donde se gestionan las relaciones con el entorno social y cultural de la escuela. Es necesario que los estudiantes participen en las distintas instancias de la comunidad escolar en las cuales se pueden tomar decisiones que afecten el funcionamiento de la escuela. Los estudiantes que representan a sus compañeros tienen voz y voto, por lo tanto deben ser responsables de sus decisiones.

La participación activa de los estudiantes significa que se puede intervenir en el diseño y en la gestión del quehacer común, salir de los intereses y proyectos personales para asumirlos de forma colectiva y trabajar en ellos con responsabilidad, dedicación y coherencia. La participación entendida desde esta perspectiva, está en la raíz de la formación democrática. La vida escolar puede y debe ser el laboratorio donde realmente se practique la participación, donde se aprenda a entender y a vivir en democracia (Casas, 2003, p. 147), para posteriormente proyectarla en el ejercicio como ciudadano.

Desde la escuela se han de brindar herramientas para la educación del niño, con el fin de entender la democracia como una forma de vida. A pesar de considerarse como un reto, muchas veces difícil, porque la educación y formación de mentalidades se ven afectadas por el contexto social, cultural y político, por eso casi siempre prima el dicho: "el ejemplo convence más que las palabras". Por ello, los estudiantes hablan de democracia en las aulas de clase en tres momentos: primero, cuando la temática hace parte de la clase de Ciencias Sociales; segundo, cuando se da el proceso electoral en la institución educativa; y tercero, cuando hay elecciones gubernamentales, ya sean locales, regionales o nacionales.

En las diferentes instancias, estamentos o comités que existen en la institución deben participar los estudiantes, es decir, ha de existir representación estudiantil 
para tener en cuenta con sus opiniones y su punto de vista, contar con voz y voto para hacer parte de las decisiones de la institución y, de esta manera, formar y educar para la democracia sensata, prudente, equilibrada y verdadera.

El docente tiene la responsabilidad de fomentar, incentivar y motivar para la participación deliberativa en todos los campos de la actividad escolar, dentro y fuera del aula escolar, tanto en las situaciones de aprendizaje como en las de relación personal. Es responsabilidad de los docentes mantener el principio de no represión mediante el fenómeno de la capacidad para la deliberación democrática de los estudiantes.

Una vez hecha una revisión general sobre la democracia y la normatividad referente a la educación, estudiamos enseguida el manual de convivencia de la escuela, como carta de navegación y donde está establecida la organización de la institución, junto con el proyecto educativo institucional.

\subsection{Clases de democracia}

Existen diversas clases de democracia en general, que se pueden aplicar a los procesos democráticos de la escuela, donde los estudiantes también pueden participar de las decisiones que se gestan en ella y que los afecta en su desarrollo personal y académico.

Tabla 3. Diversas clases de democracia

\begin{tabular}{|c|l|}
\hline CLASE & \multicolumn{1}{|c|}{ DEFINICIÓN } \\
\hline Directa & $\begin{array}{l}\text { Es aquella donde una samblea de todos los ciudadanos votan las leyes y designa a } \\
\text { los titulares del poder judicial y del poder lejislativo. }\end{array}$ \\
\hline Representativa & $\begin{array}{l}\text { En esta los ciudadanos eligen una o varias asambleas que dictan las leyes y designan } \\
\text { los responsables del poder ejecutivo monocamarista si tiene una solo asamblea o } \\
\text { bicamarista si tiene dos asambleas. }\end{array}$ \\
\hline Parlamentaria & $\begin{array}{l}\text { Es la democracia en la que el pueblo delega todos sus poderes en una o varias } \\
\text { asambleas que eligen al poder ejecutivo. }\end{array}$ \\
\hline Presidencial & $\begin{array}{l}\text { Aquí el pueblo elige sea por sufragio universal directo, o sea por sufragio universal } \\
\text { indirecto, a los representantes del poder ejecutivo. }\end{array}$ \\
\hline $\begin{array}{c}\text { De tipo } \\
\text { monárquico }\end{array}$ & $\begin{array}{l}\text { Supone la existencia de un soberano que "reina y gobierna", pero simboliza la } \\
\text { perpetuidad de la nación. }\end{array}$ \\
\hline Popular & $\begin{array}{l}\text { Han sido llamadas democracias populares el régimen comunista donde las decisiones } \\
\text { son sujetas a votación, pero propuestas y ejecutadas por el único partido existente: } \\
\text { el comunista. }\end{array}$ \\
\hline
\end{tabular}


Estas clases de democracia contribuyen a verificar que no es un proceso cerrado sino que la democracia es abierta, que construye una sociedad más justa y equitativa, pues permite profundizar en el liderazgo, en el proceso de elegir y ser elegido, de representar a los demás y velar por los interés comunes.

\subsection{Democracia y poder en la escuela}

La escuela se constituye en un aspecto que atañe al ámbito escolar, implica comprender el sentido que este tiene para estudiantes, maestros, padres y madres de familia, en cuantos actores involucrados en el proceso educativo. La democracia, "como actitud frente a la vida, dice también de la cultura de un grupo humano en un escenario determinado. Una actitud democrática es, ante todo, un acto del ser pensante que busca adoptar deliberadamente una postura frente a las interacciones, desde el reconocimiento de sí mismo y de los otros" (Borrero, 2003, p. 34). En este sentido, la democracia es una construcción colectiva que exige una verdadera reflexión.

La escuela se constituye en un espacio de relaciones, en cuya cotidianidad se configura una microcultura. En ella bien podría constituirse el significado de la democracia y de los derechos humanos, siendo a su vez escenario de los compromisos de acción que estos generan. Tomamos apartes del libro Educación y democracia: un campo de combate, del filósofo Estanislao Zuleta, pero de manera especial del capítulo titulado: "La participación democrática y su relación con la educación", en el que Zuleta afirma:

Hay un sentido de la democracia que consiste en dar derecho al otro para que exponga y desarrolle su punto de vista... Democracia es dejar que los otros existan y se desarrollen por sí mismos. Llamamos democracia al derecho al derecho del individuo a diferir de la mayoría, a pensar y vivir distinto; en síntesis: el derecho a la diferencia (Zuleta citado por Borrero, 1999, p. 34).

Desde la casa se enseña y aprende la democracia, pero en la escuela se comparte con otros fuera del núcleo familiar, y allí se hace necesario cultivar el derecho a la diferencia en todo el sentido de la palabra, diferencia de raza, religión, credo, género, etc. Es donde el niño afianza este y muchos valores en el enlace de una relación social con los demás niños y los actores de la comunidad educativa.

En el capítulo mencionado, Estanislao Zuleta aborda elementos muy importantes acerca de la democracia, como sus dificultades, sus fragilidades, modestias y su relación con la educación. "Hay muchas cosas que se imponen a los niños, que también nos impusieron a nosotros y que, aunque perfectamente arbitrarias, son 
necesarias. Hay normas que son comunes a todos porque son prerrequisitos para podernos entender..." (Zuleta, 1995, p. 134). A pesar de normas preestablecidas, también otras se pueden concertar a través de la democracia y el gobierno escolar para ser consignadas en el manual de convivencia. Por ello es importante que dejemos actuar a los niños con espontaneidad, pero debemos decirles también, con toda franqueza, si lo que han hecho está bien o no, para que puedan tener la alegría de hacer las cosas bien.

En la educación que se brinda en la escuela es importante adquirir el amor a vencer las dificultades reales. A través de la participación y el ejercicio de la democracia, de elegir y ser elegido, se expresa la espontaneidad sin temor, se es capaz de demostrar la valentía con respeto y responsabilidad por sí mismo y por los demás, se pueden plantear soluciones acertadas a problemáticas reales y buscar ayuda para transformar la realidad.

Idealmente, un espacio institucionalizado de socialización como la escuela crea unas normas de justicia que buscan proteger a sus miembros de la arbitrariedad, asignando derechos y deberes, estableciendo ciertas reglas justificadas, que procuran asegurar un manejo imparcial de diversas situaciones de la vida escolar.

Se supone, así mismo, que las normas y reglas referidas a la justicia y la democracia en la escuela han de garantizar un trato consecuente y justo, una actitud tolerante y un respeto por los derechos de todos los actores involucrados; sin embargo, en la realidad de una escuela la aplicación estricta de la norma puede dar lugar muchas veces a injusticias y faltas de concertación democratizada.

\subsection{Función política del educador}

Conviene distinguir con toda claridad el papel político del educador como reproductor y transformador de la cultura y la formación integral de los estudiantes. La primera razón de la profesión docente es la relación con la sociedad, el maestro es por esencia un actor político, "de la calidad que tenga la formación escolar depende en alto grado la oportunidad de participar en las funciones de dirección del Estado..." (Cajiao, 2004, p. 233-234).

Es necesario que en la escuela se brinden espacios de formación democrática y es el docente, como un actor político y desde su cátedra, quien debe conservar la neutralidad y prudencia para orientar, formar a los estudiantes sin matricularse en ningún partido o corriente política, para formar las mentes jóvenes en la dirección de los destinos de la sociedad con una preparación crítica. 
Es importante democratizar la educación y la escuela con el fin de formar niños analíticos y críticos de la realidad, capaces de participar, proponer y hacer parte del proceso ejercitado en la democracia, y por eso es necesario:

1. Devolver la escuela a todos sus actores y permitir que se relacione con la realidad social circundante.

2. Romper las barreras de discriminación que atentan contra los derechos fundamentales de la persona.

3. Garantizar la formación de ciudadanos activos a través de prácticas de democracia escolar.

Dentro de la escuela es importante promover la participación activa de los estudiantes en la gestión escolar. Es muy fácil de boca para afuera y en la teoría, pero difícil de llevar a la práctica, pues implica ceder y poder. Una organización democrática se opone a una organización autocrática, pero desafortunadamente en la escuela reina casi siempre lo segundo, y si no veamos la implementación de la disciplina y las formalidades de horarios, uniformes, silencio y todas las prohibiciones que si bien hacen parte de la formación, no tienen una adecuada ejecución.

\subsection{El maestro, dinamizador de este proceso}

El conocimiento y la comprensión del proceso de grupo es la contribución más importante que el maestro puede hacer a cualquier conjunto de niños. Por ello, el maestro "debe atraer la atención de los niños hacia ese proceso, por la misma forma como él mismo trabaje. El maestro pone en movimiento y guía su desarrollo" (Lindberg, 1961, p. 16), el maestro debe aprender las aptitudes que demandan la definición de las necesidades de planes y la labor conjunta para realizarlos, así como utilizar los resultados de una valoración cuidadosa y para ello requiere mucha práctica y mucho estudio. No se puede esperar que los niños y jóvenes aprendan tales cosas por el solo hecho de escuchar las explicaciones en la teoría.

El deber del "maestro es ayudar a los niños a examinar los problemas y a recurrir al proceso de un grupo en busca de su solución. A los niños se les puede enseñar a que reconozcan la importancia de todos los elementos que figuran en el proceso de la democracia" (Lindberg, 1961, p. 16), y además a que adquieran pericia en el empleo de ellos y de los valores que se requieren para la rectitud del desarrollo del proceso. El maestro no necesitará dedicar todo su tiempo y toda su atención a lo técnico y procedimental, sino que el especialista del proceso democrático prestará sus servicios en muchas direcciones. 
El maestro necesita conocer y comprender las características de los niños, debe tener amplia práctica y desear que su experiencia aumente. Para trabajar en la forma democrática se necesita pensar profundamente acerca de muchos asuntos, tanto desde el punto de vista del niño como desde el del adulto. El maestro debe conocer perfectamente los problemas de la comunidad, para así poder ayudar a los niños a encontrar la forma de estudiar y resolver aquellos problemas que los afectan más directamente.

El maestro "necesita también comprender los problemas sociales, en su niveles local, nacional e internacional, para ayudar a los niños a que vean esos mismos problemas desde un punto de vista cada vez más amplio" (Lindberg, 1961, p. 17); debe recurrir a la experiencia de los niños para ayudarlos y enseñarles a resolver los problemas y dificultades a través del proceso democrático.

Se ha de preparar a los maestros para que, aparte de ser especialistas en el proceso, también se constituyan en protagonistas del cambio educativo, en el sector educativo, "el papel de los docentes como protagonistas del cambio educativo" (Cárdenas, 2000, p. 22), y dicho cambio se debe generar desde un proceso de democracia en el interior de las escuelas, que luego debe transcender al exterior de las mismas, y también cuando el estudiante ya esté en la edad de ciudadano.

\subsection{Gobierno escolar como una forma de acercamiento a la democracia en la escuela}

Se abordará desde su concepto, propósitos y beneficios del gobierno escolar, como una organización de los niños, donde cada miembro participa democráticamente en actividades de la escuela, buscando el desarrollo social y afectivo de los educandos.

El gobierno escolar es una estrategia social y metodológica que abre un espacio para que los alumnos se expresen como comunidad estudiantil responsable, que propone desarrollar proyectos que les permitan generar y enriquecer su propia vida escolar. La Ley 115 de 1994 (capítulo IV, artículo 18) pretende que todos los miembros de la comunidad educativa, conformada por estudiantes, padres de familia o acudientes, maestros, directivos docentes y administradores, exalumnos y representantes del sector productivo, todos ellos según su competencia, participen en el diseño, ejecución y evaluación del proyecto educativo institucional y en la buena marcha del respectivo establecimiento educativo. En otras palabras, el gobierno escolar es una respuesta a la necesidad de participación real y efectiva, exige tomar conciencia, tener actitud de compromiso, e identidad profesional e institucional. 


\subsubsection{Propósitos del gobierno escolar}

Se consideran de vital importancia para el desarrollo dinámico de la comunidad educativa, los siguientes:

1. El fin del gobierno escolar es estimular el desarrollo socio-afectivo del niño e iniciarlo en la vida cívica y democrática.

2. Esta innovación tiene como objetivo principal la integración de todos los elementos que componen la escuela, así como el desarrollo socio-afectivo e integral de los estudiantes.

3. Desarrollar en los educandos actitudes y valores, mediante la participación democrática en las diversas actividades escolares.

4. La escuela nueva, a través de la acción del gobierno escolar, pretende devolverle al alumno su derecho de opinar, de participar, de integrarse al medio y de exigir un dialogo claro y razonable.

5. La formación de valores como responsabilidad, honestidad, solidaridad, justicia, participación y otros de gran importancia para el niño.

6. Formar y fomentar en los alumnos prácticas democráticas como la libre participación, el derecho de elegir y ser elegido.

7. El gobierno escolar tiene como propósito principal la integración de la comunidad educativa; padres de familia, estudiantes y maestros.

\subsubsection{Beneficios del gobierno escolar}

Se abordan en tres dimensiones, para la comunidad, los maestros y los niños, tal como se indica a continuación: 
Tabla 4. Beneficios del gobierno escolar

\begin{tabular}{|c|c|}
\hline ENTE & BENEFICIOS \\
\hline Comunidad & $\begin{array}{l}\text { 1. Fortalece las relaciones comunitarias, ya que la administración y el trabajo de la } \\
\text { institución son conjuntos, comunitarios, participativos, con la colaboración de todos. } \\
\text { 2. Los padres de familia participan activamente de las actividades encomendadas a } \\
\text { sus hijos. } \\
\text { 3. Forma líderes comunitarios; promueve el civismo y la socialización en la escuela } \\
\text { y la comunidad. } \\
\text { 4. Integra a los padres de familia para que participen más activamente en las actividades } \\
\text { de la escuela. } \\
\text { 5. El niño en el gobierno escolar va fomentando su espíritu de defensa, conservación, } \\
\text { recuperación, sobre todo en lo que corresponde a lo político y el bienestar de la } \\
\text { comunidad. }\end{array}$ \\
\hline Maestros & $\begin{array}{l}\text { 1. Mediante la práctica de esta experiencia se conocen aspectos importantes del } \\
\text { comportamiento familiar en los hogares de los niños, la manera de pensar frente a } \\
\text { los dirigentes y gobernantes, a los procesos electorales y a las campañas políticas, } \\
\text { que de una u otra forma afectan el desenvolvimiento del estudiante, en el presente y } \\
\text { el futuro. } \\
\text { 2. Es una nueva fuente de información para conocer las características particulares } \\
\text { de los estudiantes que, bien orientados, pueden contribuir a mejorar el producto } \\
\text { sociopolítico del material humano que está en nuestras manos. } \\
\text { 3. El trabajo del gobierno escolar facilita las actividades del maestro, quien sin } \\
\text { descargar totalmente su responsabilidad, pero si ha encontrado su mano derecha } \\
\text { para miles de tareas que se presentan en la escuela; es este apoyo a la labor docente } \\
\text { y facilita el desarrollo de las labores internas de la escuela. }\end{array}$ \\
\hline Niños & $\begin{array}{l}\text { 1. El estudiante es el centro del proceso educativo: el gobierno escolar busca iniciar } \\
\text { al niño en una educación cívica y ciudadana y promueve la participación democrática. } \\
\text { 2. Como propuesta educativa el gobierno escolar inicia al niño en los fundamentos } \\
\text { básicos dentro de una sociedad participativa, reafirma y crea valores en el desempeño } \\
\text { de funciones que son designadas y tomadas por él. } \\
\text { 3. A través del gobierno escolar el niño vive una verdadera democracia en la escuela } \\
\text { donde la práctica de ésta, fomenta una serie de valores y permite el despliegue de } \\
\text { habilidades y destrezas de diversa índole por parte de los niños, proporcionando } \\
\text { además un ambiente favorable para la formación de líderes responsables que auto } \\
\text { gestionan y dan alternativas de solución a las necesidades prioritarias, hoy en la } \\
\text { escuela, mañana en la comunidad. } \\
\text { 4. El gobierno escolar desarrolla en el niño el sentido pertenecer al grupo, llevan al } \\
\text { estudiante a la participación activa y a fortalecer los valores de respeto por sus } \\
\text { compañeros, responsabilidad, entre otros } \\
\text { 5. Los niños se sienten parte activa del establecimiento y por lo tanto luchan y se } \\
\text { esfuerzan por el mejoramiento institucional y administrativo de su escuela, es decir, } \\
\text { sentido de pertinencia. } \\
\text { 6. El desarrollo cognoscitivo con el gobierno escolar favorece la libre expresión, la } \\
\text { formación de actitudes críticas y responsables, la coordinación de las ideas de los } \\
\text { niños, la tolerancia, el respeto mutuo mediante la participación en grupos de trabajo. } \\
\text { 7. El estudiante mantiene relaciones democráticas tanto en la vida familiar como en } \\
\text { la vida social, se va comprendiendo así mismo, con la mayor objetividad, reconociendo } \\
\text { sus propios sentimientos, interese, valores y limitaciones fortaleciendo vínculos que } \\
\text { favorezcan su identidad y el progreso de la sociedad. }\end{array}$ \\
\hline
\end{tabular}


El gobierno escolar es una respuesta a la necesidad de asociación real y efectiva, exige toma de conciencia, compromiso, identidad profesional e institucional, donde aparece la autonomía como realidad que debemos apoyar y reconocer promoviendo comunidades con participación, democracia, respeto a los derechos humanos y construcción de valores para la sociedad futura; con la mirada puesta en el niño, el adolescente, el adulto, el anciano, la familia y la escuela de una manera integrada hacia la transformación ciudadana.

La autonomía en el gobierno escolar implica responsabilidad, compromiso con el análisis sistemático de los problemas, exploración de las soluciones y la apertura indispensable para cualificar, enriquecer los proyectos institucionales y pedagógicos que se formulen, ya que esto requiere trabajo colectivo, reflexiones, crítica constructiva y eficacia en la producción de alternativas, como cambios permanentes en función de mejorar la calidad de educación y formación.

Por tal motivo, el gobierno escolar es una oportunidad para que los niños generen actitudes de integración, trabajo en equipo, liderazgo, convivencia y conocimiento para la conservación de una escuela democrática a través del ejercicio práctico de la cívica mediante el voto programático, tarjetón, urna, revocatoria de mandato, campaña política, entre otros aspectos del ejercicio de una democracia sana, donde haya la oportunidad para una adecuada educación en el ejercicio acertado de la democracia desde la escuela.

\subsubsection{Estrategias para el ejercicio de la democracia}

Convertir la escuela en un ambiente de convivencia garantizando la participación de todos los estamentos escolares mediante diálogos, sugerencias, libre expresión, organizando mesas redondas, debates, encuestas y talleres para darle la oportunidad de manifestar sus ideas a los padres de familia, estudiantes y maestros.

Es una oportunidad para el ejercicio de libre expresión, en el que todas las vivencias son válidas, puesto que se recogen percepciones individuales y grupales de la misma problemática donde cada participante expresa su posición. Además de los estudiantes, también se permite la participación de los padres de familia en la elaboración del manual de convivencia, en el que se plasman los derechos y deberes de los mismos. Por ello la organización del gobierno escolar es una estrategia participativa y democrática, pues es la forma de incorporar más activamente a los diferentes actores educativos en la vida de la escuela.

Para la conformación del gobierno escolar se han de tener en cuenta la Ley 115 y el Decreto 1860 de 1994, a fin de obtener una organización y conformación correcta 
del mismo; desde el consejo directivo, académico, consejo estudiantil, el personero y demás entes que hacen parte de los organismos de participación en la democracia de la escuela y que deben estar consignados, al menos, en un capítulo del manual de convivencia de la escuela. Allí también deben estar determinadas las funciones de cada organismo de participación, para la claridad y manejo de estos dentro de un control previamente establecido. También deben estar establecidos los pasos para las elecciones de los representantes a cada ente; de esta forma se convierte el manual de convivencia en la carta magna de la escuela, para la dinámica organizativa del gobierno escolar.

En este proceso se encuentran paradojas y trampas, como dice Santos (1996): "Es una institución cargada de imposiciones, que pretende educar para la participación. Casi todo está prescrito en la escuela; sin embargo, se insiste en la necesidad de que los alumnos sean creativos y participativos en el desarrollo del currículo". Y así continúan otras paradojas y trampas sobre la imposibilidad de construir democracia donde quizás ya está todo dicho y escrito. Un ejemplo en una institución educativa: una de las estudiantes que aspiraba a la personería de su colegio marcó unas pelotas y se las entregó a los niños con el fin de hacer campaña, según las directivas fue un inadecuado proceder y fue tachado de politiquería, le impidieron terminar de entregarlas, le ordenaron recoger las que había donado y fue sancionada.

De lo anterior se pueden extraer dos enseñanzas: por una parte, la influencia de la vida política que existe en la realidad de los tiempos actuales, y por otra, las consecuencias de una inadecuada formación de la democracia. Esa posibilidad de campaña electoral terminó en castigo y las alumnas que tenían mayor opción de ganar, salieron decepcionadas de haber participado; la institución, en vez de educar para estructurar de manera adecuada la campaña electoral y el manejo del proceso, terminó por hacer cumplir normas que ni siquiera estaban establecidas en el manual de convivencia.

En otra institución, los estudiantes candidatos de primaria y undécimo realizaron la campaña y expusieron su programa ante sus compañeros de la escuela. Tanto los unos como los otros actuaron como un político tradicional, en la apertura y cierre de sus campañas, con sus seguidores más cercanos. Las elecciones se desarrollaron según lo establecido por el área de Ciencias Sociales. En cuanto a la logística, el área recurrió a la Registraduría (1996) para el préstamo de mesas y cubículos en los que los estudiantes cumplieron con el ejercicio del sufragio, según las listas de las mesas a las cuales se habían escrito y donde debían depositar su voto por el candidato de su preferencia.

En realidad no sucede un inadecuado proceder en todos los establecimientos educativos, pues se visitó una escuela que estaba en proceso electoral, donde se 
nombraban los representantes a los diferentes entes del gobierno escolar: consejo directivo, consejo académico, personero y consejo estudiantil, el cual se desarrolló de manera normal.

\section{Conclusiones}

Se trataron de manera general algunas concepciones de la democracia, la historia del voto en Colombia y como ha transcendido en las instituciones educativas, por ello podemos afirmar que se ha comenzado a forjar cultura ciudadana desde la escuela como centro educativo.

Es significativo sufragar, porque el voto es, ante todo, un acto personal y de voluntad; además, es un derecho y un deber de todos, por el hecho de formar parte de la comunidad estudiantil.

A los estudiantes hay que indicarles que no deben dejar que otros decidan por ellos, es necesario que sean partícipes de las decisiones, es importante que hagan parte del ejercicio de la democracia en la escuela, a través del gobierno escolar.

Es necesario educar y formar a los niños desde del hogar, después en la escuela y también en la comunidad, para que haya una integración que permita fomentar la socialización, pues el gobierno escolar es un medio para fortalecer la comunicación e integración entre los actores educativos y la comunidad educativa.

El docente es el llamado a orientar de manera prudente y forma neutral el desarrollo de valores y la práctica de la democracia en la escuela, para que haya una verdadera integración con el medio social y una relación armoniosa entre los diferentes actores educativos. Los padres de familia y la comunidad en general muestran interés y aceptación por los cambios en la educación, y, por tal razón, se han querido integrar a las diferentes actividades por desarrollar, para que estén más cerca del proceso educativo y fomenten el desarrollo de la democracia en la escuela, y, de esta manera, se fortalezca la proyección del ejercicio de la democracia en la comunidad.

El ejercicio de la democracia en la escuela se puede evidenciar en la propuesta del gobierno escolar, es allí donde es posible tener la experiencia de la democracia en la comunidad educativa e integrar a los diferentes actores educativos: padres de familia, maestros, estudiantes y comunidad en general, con el fin de construir una sociedad más justa y equitativa desde el lugar donde se comienzan a forjar grandes líderes estudiantiles y hacia el futuro líderes de la sociedad con nuevas alternativas de solución a problemas y necesidades comunitarios. 


\section{Referencias}

Aristóteles, (2000). La Política (1 a ed.). Bogotá: Momo.

Bernal, J. L. M. et al. (1995). El gobierno escolar como una forma de acercamiento a la democracia en la escuela. Tesis de grado. Instituto de Educación Abierta y a Distancia, Universidad pedagógica y Tecnológica de Colombia. Tunja, Boyacá, Colombia.

Borrero, G. C. (comp.) (1999). Gobierno escolar y democracia. (1ª ed.). Bogotá: Antropos.

Cajiao, F. (2004). La formación de maestros y su impacto social. Bogotá: Magisterio.

Casas, V. M. et al. (2003). La democracia y sus retos en el siglo XXI. Elementos para la formación democrática de los jóvenes. Barcelona: Muriel.

Cárdenas, A. L. et al. (2000). El maestro protagonista del cambio educativo. Bogotá: Magisterio.

Constitución Política de Colombia. (2008). Bogotá: Momo. Dewey, J. (1990). Administración de las instituciones escolares. Bogotá: Universidad de la Sabana.

González, F. J. et al. (1998). Educar para la democracia. La ciencia-tecnologíasociedad. Investigación en la escuela. Democracia y renovación de la escuela, 34, 59-67.

Gil, F. (1997). La participación democrática en la escuela. De cómo los agentes educativos se las ingenian para gobernarse. Santa Fe de Bogotá: Magisterio.

Lindberg, L. (1961). La democracia en la escuela. México: Letras.

Locke, J. (1995). Tratado sobre el gobierno civil. Bogotá: Momo.

Montesquieu, (2000). El espíritu de las leyes. Bogotá: Momo.

Platón, (2000). La República. Bogotá: Momo. Registraduría Nacional del Estado Civil (1996). Democracia para los jóvenes. Bogotá: s.n.

Rodríguez, M. (2008). La democracia como una forma de vida en el aula del grado $5^{\circ} \mathrm{D}$ en la institución educativa San Marcos de Muzo, Boyacá. Tesis de grado. Facultad de Estudios Tecnológicos y a Distancia, Universidad pedagógica y Tecnológica de Colombia. Tunja, Boyacá, Colombia.

Rousseau, J. J. (2000). El contrato social. Bogotá: Momo.

Santos, G. M A. (1996). La democracia, un estilo de vida. Cuadernos de Pedagogía, Barcelona, 251, 50-54.

Zuleta, E. (1995). Educación y democracia. Un campo de combate. (2 a ed.). Bogotá: Corporación Tercer Milenio. 